\title{
Feasibility Study of Flotation Process in Separating Chicken from Chicken Skeleton
}

\author{
Erqing Jin, Cong Peng, Shun Liao, Jianzhong $\mathbf{W u}^{*}$ \\ Department of Food Science and Engineering, Jinan University, Guangzhou, China \\ Email:JIN132491@163.com, ${ }^{*}$ twjzh@jnu.edu.cn
}

How to cite this paper: Jin, E.Q., Peng, C., Liao, S. and Wu, J.Z. (2016) Feasibility Study of Flotation Process in Separating Chicken from Chicken Skeleton. Food and Nutrition Sciences, 7, 1375-1385. http://dx.doi.org/10.4236/fns.2016.714125

Received: November 21, 2016 Accepted: December 16, 2016

Published: December 19, 2016

Copyright $\odot 2016$ by authors and Scientific Research Publishing Inc. This work is licensed under the Creative Commons Attribution International License (CC BY 4.0).

http://creativecommons.org/licenses/by/4.0/

\begin{abstract}
An innovative and effective method of separating chicken meat and bone from chicken skeleton was developed in this study. Different heating approaches to chicken skeleton were compared to optimize cooking conditions including cooking temperature and cooking time. The separation efficiency of chicken meat and bone in different conditions, including flow direction, impeller speed and the liquid level rising velocity were also studied. Experimental results demonstrated high temperature cooking and assisted mechanical stirring could improve separating rate of chicken skeleton. Liquid flow entering at tangent entrance direction of the kettle could maintain the stability of the liquid level and smoothness of the separation process. The outflow rate of chicken meat increased as the liquid level rising velocity raised, and approached to the maximum value at $0.80 \mathrm{~cm} / \mathrm{s}$. The practical application test showed that the best conditions for separation of chicken skeleton were: $45 \mathrm{~min}$ cooking time at $114^{\circ} \mathrm{C}$; tangent flow direction; stir speed of $200 \mathrm{r} / \mathrm{min}$; the liquid level rising velocity of water is $0.8 \mathrm{~cm} / \mathrm{s}$. Using this approach, the value of chicken bone was increased, product specialization was enhanced, and the results could be used in future high value chicken product development.
\end{abstract}

\section{Keywords}

Chicken Skeleton, Separation, Flotation, Bone, Meat

\section{Introduction}

According to the national economic and social development statistics released by the National Bureau of Statistics in 2013, the annual output of Chinese poultry is $17,890,000$ tons [1]. China's annual processing of poultry skeleton is more than $3,000,000$ tons, of which the fresh chicken skeleton accounted for more than 1,500,000 tons. Chicken 
skeleton is leftover after removing the chicken breast which consists of high nutritional value [2]. It contains $20 \%-25 \%$ of fat, $12 \%-35 \%$ of protein, and have high amount of collagen and calcium [3].

The current poultry processing technology and equipment in China are unable to separate chicken meat from chicken skeleton completely [4]. There is still residual fresh meat remaining on the chicken skeleton. In China, the chicken bones are normally crushed into powder and used in the preparation of chicken bone paste or other similar products [5] [6] [7].

By using ultrafine grinding processing method, United States, Japan and other countries convert chicken skeleton into mud, mud meaty, bone meal, and then processed into bone paste, made of cancellous bone, bone MSG, white meat sauce and other products, but these products do not meet the Chinese diet and did not solve the high amount of the domestic chicken skeleton utilization problems completely [8] [9]. The key to solve these problems is to study the characteristics of chicken skeleton and to separate chicken skeleton into chicken meat and chicken bone. Based on these, we intended to develop downstream products, and then make the best use of them [10].

Using different high pressure cooking on chicken skeleton [11], the optimum condition of processing was explored. The law of motion in the fluid of chicken meat and bone were studied based on the flotation theory. In this paper, the optimum separation condition of the chicken skeleton was determined, and satisfactory results were obtained in the practical application. The chicken meat isolated from the chicken skeleton can be processed into high quality chicken powder, ground chicken, and chicken jerky [12]. The bone of chicken skeleton can be processed into chicken bone power that can be used as a source of calcium supplement [13] [14]. The rest of the chicken soup can be used as raw material for concentrated chicken soup. Through a reasonable processing, we can turn the chicken skeleton into treasure by improving the utilization rate and increase the value of chicken skeleton [15]. It will have broad application prospects as this can not only saving resources but also reduce environmental pollution [16].

\section{Materials and Methods}

\subsection{Materials}

Chicken skeleton was obtained from Jinan market and stored at $-18^{\circ} \mathrm{C}$. It was unfreezed before use.

\subsection{Processing Craft}

The processing flow is shown in Figure 1.

\subsection{Operational Principle and Features}

It can be seen the schematic diagram of the equipment in Figure 2.

The chicken bone and meat filtered out from the chicken soup were poured into the separation tank(a) after cooking; filled half tank of water to water-storage tank and then pump was started and the water was pumped into the separation $\operatorname{tank}(a)$. When filled 


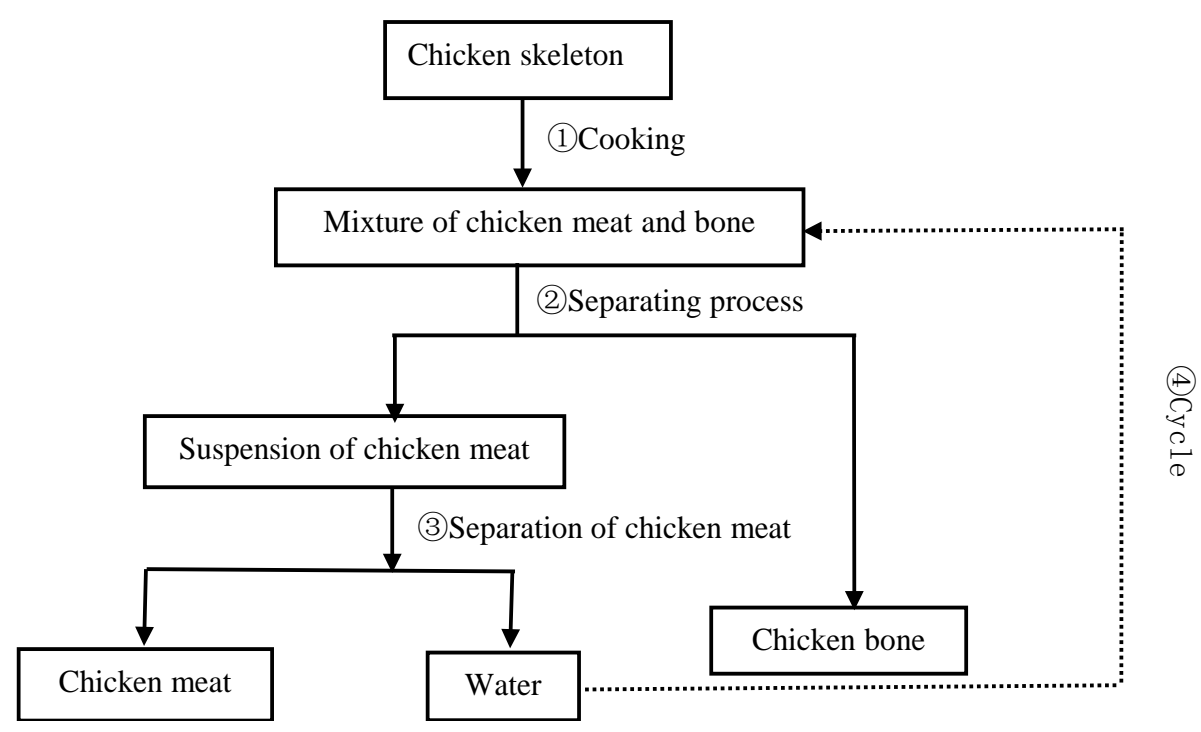

Figure 1. Processing craft of the separation equipment.

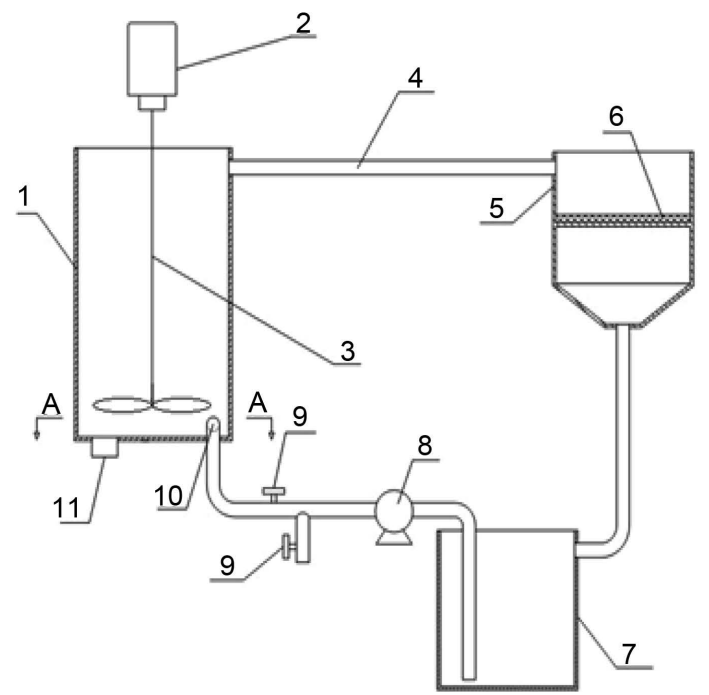

(1)
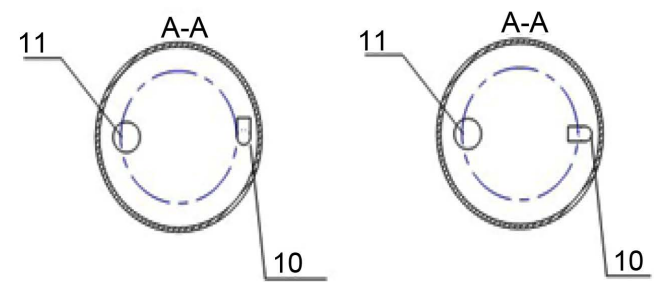

Figure 2. Schematic diagram of the separation equipment. (Each numbers in the figure corresponding to the followings: 1 , separating $\operatorname{tank}(\mathrm{a})$ : diameter, $30 \mathrm{~cm}$, height, $30 \mathrm{~cm} ; 2$, electric generator; 3 , mixing propeller; 4, pipeline; 5 , separation tank(b); 6, filter (60 mesh); 7, water-storage tank: diameter, $40 \mathrm{~cm}$, height, 40 $\mathrm{cm}$; 8, pump; 9, valve; 10, feed liquid entrance; (1) tangential direction (2) in radial direction; 11, discharge hole for bone).

the separating $\operatorname{tank}(a)$ with half tank of water, the electric generator started to work and mixing propeller begin to stir which accelerates the separation of chicken meat and bone. According to buoyancy force of water, chicken meat was forced through filter in the separation tank(b) by pipeline. The chicken meat stayed on the filter, while the water flowed back into water-storage tank again, and enter the next cycle. The chicken skeleton cycle would last for 5 minutes, and the bone was discharged through discharge hole. In the end, chicken meat and chicken bone were completely separated from chicken skeleton. Pure chicken, chicken bone and soup were successfully obtained. 


\subsection{Pretreatment of Chicken Skeleton}

Chicken skeleton was cooked with pressure cooker and common stainless steel kettle separately. The time was started to calculate once boiling was achieved for stainless steel kettle. While, for pressure cooker, the time started when air valve was uplifted, the working pressure was $0.18 \mathrm{Mpa}$ (combined with standard atmospheric pressure) and temperature reached $114^{\circ} \mathrm{C}$. Heating process was stopped when the scheduled time of $30 \mathrm{~min}$ and $45 \mathrm{~min}$ was reached.

\subsection{Weight Determination Method}

The separation products of chicken meat and bone were weighted after staying for 10 min on the stainless steel filter screen of 60 mesh.

\subsection{Statistical Analyses}

Drawing with Origin 7.5, data were analyzed using a one-way analysis of variance (ANOVA). Mean separation was done by the Duncan's multiple range test using SPSS version 17.0. Differences were considered statistically significance at $\mathrm{P}<0.05$.

\section{Results}

\subsection{Cooking Process}

One kilogram fresh frozen chicken skeleton were prepared, and water was added at the rate of 1:1 (w:w). Cooked chicken skeleton was obtained by different cooking process at $100^{\circ} \mathrm{C}$ for $45 \mathrm{~min}$, and $114^{\circ} \mathrm{C}$ for $30 \mathrm{~min}$ and $45 \mathrm{~min}$ respectively. In this process, transformer to control electrical power was used, and kept the contents in simmer state. Then, the cooked chicken was filtered out from the chicken soup. It was cooled to room temperature and poured into the separation vessel 1 . The separating vessel 1 was filled with half tank of water, then the power of the electric machinery 2 was turned on, and paddle 3 began to stir at $200 \mathrm{r} / \mathrm{min}$ to mix the compounds. This process would last for 2 min. After that, the chicken bone and chicken meat was obtained from chicken skeleton. Residual meat from the bone was collected and weighted after staying for $10 \mathrm{~min}$ on the stainless steel filter screen of 60 mesh. The results are shown in Table 1.

\subsection{Liquid Injection Direction}

\subsubsection{Influence of Liquid Injection Direction on the Rate of Outflow of Chicken Meat}

One kilogram of prepared chicken meat was weight and put into separate container.

Table 1. Effect of different heating approaches to chicken skeleton.

\begin{tabular}{cccc}
\hline Group & Heating temperature $\left({ }^{\circ} \mathrm{C}\right)$ & Heating time $(\mathrm{min})$ & Outflow of chicken meat $(\%)$ \\
\hline A & 100 & 45 & $46.33 \pm 3.76^{\mathrm{a}}$ \\
B & 114 & 30 & $81.33 \pm 3.48^{\star \mathrm{b}}$ \\
C & 114 & 45 & $93.01 \pm 0.29^{* \mathrm{c}}$ \\
\hline
\end{tabular}

Values are expressed as Mean $\pm \mathrm{SE}$; ${ }^{\star} \mathrm{P}<0.05$, within a column, means followed by different letters were significantly different at level of 0.05 ; LSD multiple comparison tests were used. 
The liquid level rising velocity and impeller speed was controlled at $0.80 \mathrm{~cm} / \mathrm{s}$ and 200 $\mathrm{r} / \mathrm{min}$ respectively. The outflow volume of meat was recorded in five minutes under the tangential and radial direction respectively. The graph of outflow rate of chicken meat against separating time at different liquid injection direction is shown in Figure 3.

\subsubsection{Influence of Liquid Injection Direction on the Rate of Outflow Rate of the} Chicken Bone

Three hundred gram of prepared chicken bone was weighed and put into the separate container. The liquid level rising velocity was controlled at $0.80 \mathrm{~cm} / \mathrm{s}$ and the impeller speed at $200 \mathrm{r} / \mathrm{min}$. The outflow volume of bone in five minutes under the tangential and radial direction was recorded. The outflow of bone was calculated. The result is shown in Table 2.

\subsection{Impeller Speed}

\subsubsection{Influence of Impeller Speed on the Rate of Outflow Rate of the Meat}

One kilogram of prepared chicken meat was weighed and put into the separate container. The liquid level rising velocity was controlled at $0.80 \mathrm{~cm} / \mathrm{s}$ and the liquid injection was set in tangential direction. The outflow volume of meat in five minutes under the impeller speed of $0 \mathrm{r} / \mathrm{min}$ and $200 \mathrm{r} / \mathrm{min}$ was recorded respectively. The plot of outflow rate of chicken meat against the separating time at different impeller speed is shown in Figure 4.

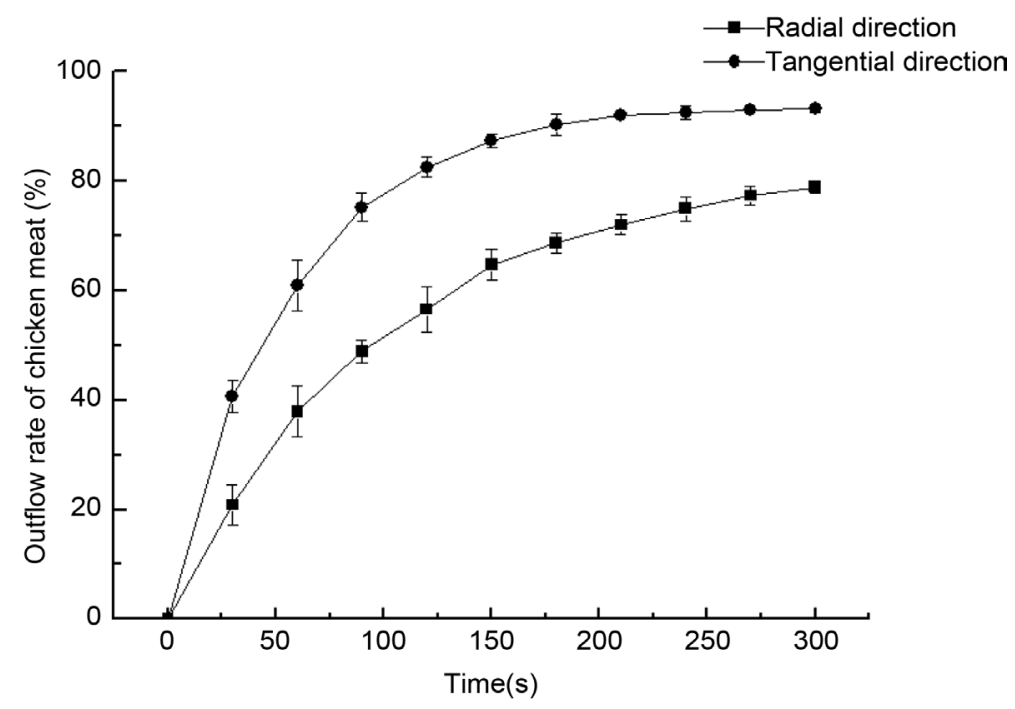

Figure 3. Influence of the liquid injection direction on the rate of outflow of chicken meat.

Table 2. Effect of flow direction on the outflow rate of bone.

\begin{tabular}{ccc}
\hline Group & Injection direction & Outflow rate of bone (\%) \\
\hline A & tangential & $0 \pm 0.41$ \\
B & radial & $5.92 \pm 1.2^{*}$ \\
\hline
\end{tabular}

Values are expressed as Mean $\pm \mathrm{SE} ;{ }^{*} \mathrm{P}<0.05$. 


\subsubsection{Influence of Impeller Speed on the Outflow Rate of the Bone}

Three hundred gram of prepared chicken bone was weighed and put into the separate container. The liquid level rising velocity was controlled at $0.80 \mathrm{~cm} / \mathrm{s}$ and the impeller speed at $200 \mathrm{r} / \mathrm{min}$. The outflow volume of bone in five minutes under the tangential and radial direction was recorded. The outflow of bone was calculated. The result is shown in Table 3.

\subsection{Liquid Level Rising Velocity}

\subsubsection{Influence of the Liquid Level Rising Velocity on the Rate of Outflow of Chicken Meat}

One kilogram of prepared chicken meat was weight and put into the separate container. The impeller speed was controlled at $200 \mathrm{r} / \mathrm{min}$ and the liquid was injected in tangential direction. The outflow volume of meat in five minutes under different flow velocity was recorded. The graph of outflow rate of chicken meat against flow velocity with increasing separating time is shown in Figure 5.

\subsubsection{Influence of the Liquid Level Rising Velocity on the Rate of Outflow of Chicken Bone}

Three hundred gram of prepared chicken bone was weighted and put into separate container. The liquid was injected in tangential direction and the impeller speed was adjusted to $200 \mathrm{r} / \mathrm{min}$. The chicken bone outflow rate was calculated under the liquid

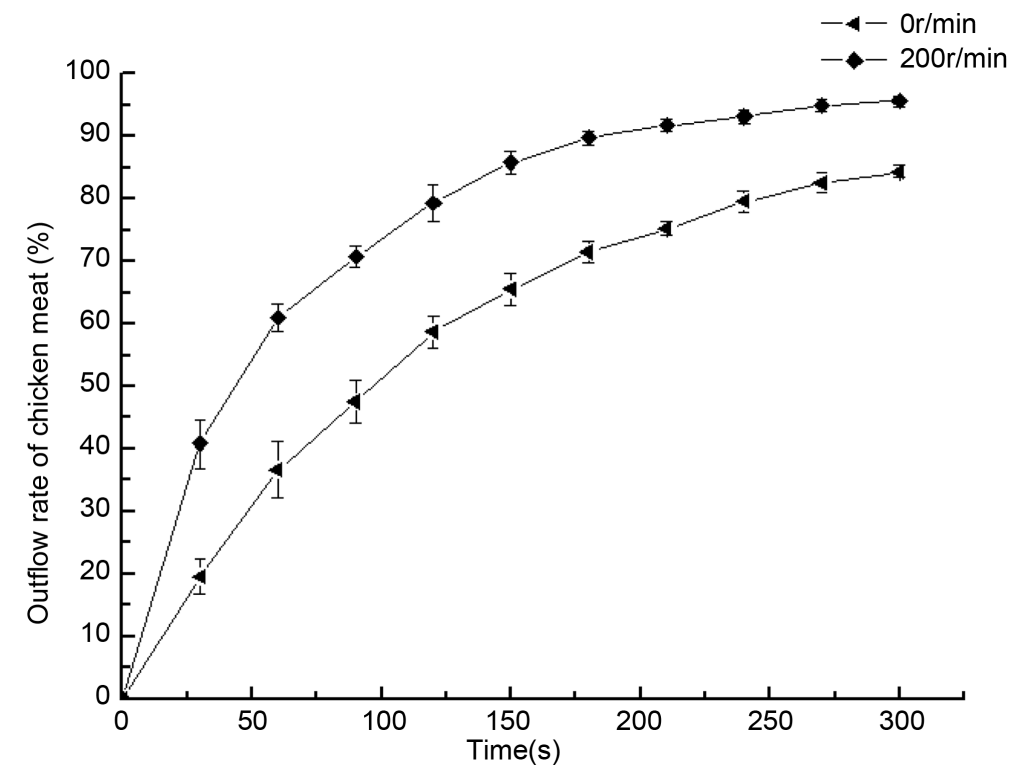

Figure 4. Influence of the impeller speed on the rate of outflow of meat.

Table 3. Effect of impeller speed on the outflow rate of bone.

\begin{tabular}{ccc}
\hline Group & Speed $(\mathrm{r} / \mathrm{min})$ & Outflow rate of bone $(\%)$ \\
\hline A & 0 & $2.77 \pm 0.64^{*}$ \\
B & 200 & $0.633 \pm 0.38$ \\
\hline
\end{tabular}

Values are expressed as Mean $\pm \mathrm{SE} ;{ }^{*} \mathrm{P}<0.05$. 
level rising velocity of $0.60 \mathrm{~cm} / \mathrm{s}, 0.80 \mathrm{~cm} / \mathrm{s}, 1.0 \mathrm{~cm} / \mathrm{s}$ and $1.2 \mathrm{~cm} / \mathrm{s}$ in both impeller speed. Result is shown in Table 4.

\subsection{Practical Application}

From the results shown in 3.2, 3.3 and 3.4 the optimum conditions whereby the liquid was injected at tangential direction, impeller speed was set at $200 \mathrm{r} / \mathrm{min}$ and liquid level rising velocity was controlled at $0.8 \mathrm{~cm} / \mathrm{s}$ not only can make most of the meat flow out of the separation vessel, but can also ensure the chicken bone remain in the separation vessel. Effective separation of chicken meat and bones can be achieved.

Two kilogram of fresh frozen chicken skeleton was weighed and put into the pressure cooker. Water was added according to the weight ratio of 1:1. After 10 minutes cooking, the cooked chicken skeleton was cooled to room temperature; the cooked chicken skeleton was poured through 40 mesh stainless steel sieve for 10 minutes to achieve a well-dispersed mixture of chicken meat and bone. The total weight of was about $1050 \mathrm{~g}$. The mixture of meat and bone was put into a separate container. The liquid level rising velocity was controlled at $0.80 \mathrm{~cm} / \mathrm{s}$, the impeller speed was set at $200 \mathrm{r} / \mathrm{min}$ and the liquid was injected at tangential direction. The outflow volume of meat and bone in 5

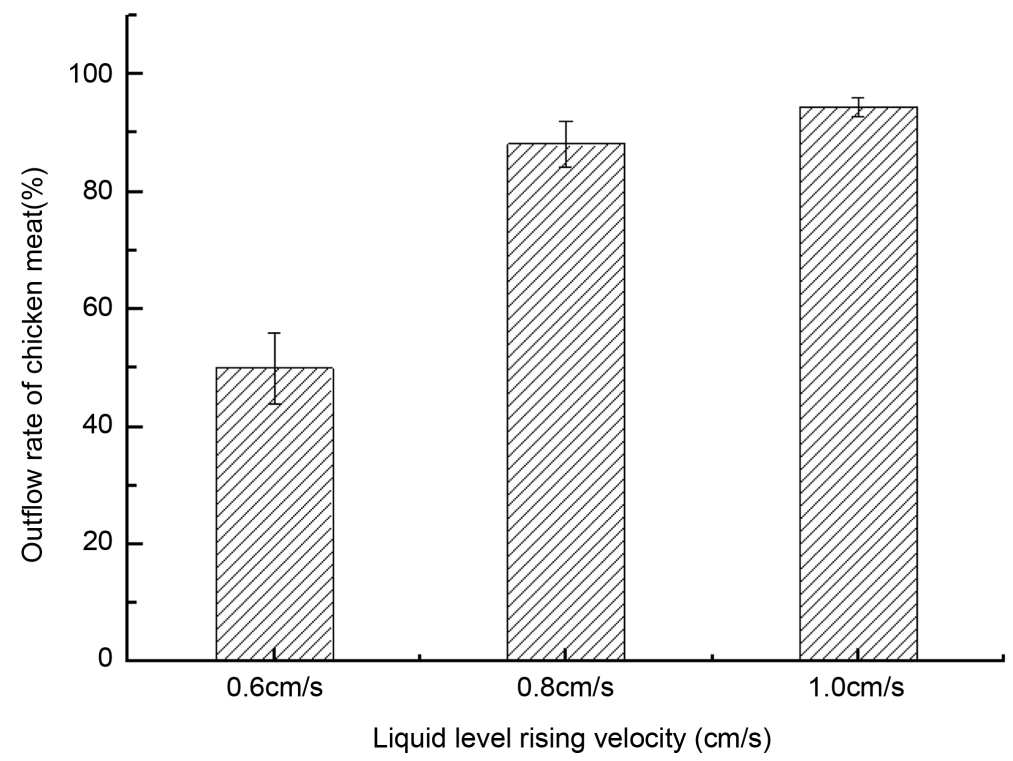

Figure 5. Influence of the liquid level rising velocity on the rate of outflow of chicken meat.

Table 4. Effect of the liquid level rising velocity on the outflow rate of bone.

\begin{tabular}{ccc}
\hline Group & Liquid level rising velocity $(\mathrm{cm} / \mathrm{s})$ & Outflow rate of bone $(\%)$ \\
\hline A & 0.60 & $0.00 \pm 0.00^{\mathrm{a}}$ \\
B & 0.80 & $0.633 \pm 0.38^{\mathrm{a}}$ \\
C & 1.0 & $3.33 \pm 0.33^{* * \mathrm{~b}}$ \\
\hline
\end{tabular}

Values are expressed as Mean $\pm \mathrm{SE}$; ${ }^{*} \mathrm{P}<0.05$, within a column, means followed by different letters were significantly different at level of 0.05 ; LSD multiple comparison tests were used. 
minutes was recorded. The weight of the outflow of crude chicken meat and bone were also recorded. The residual bones in crude chicken meat and residual meat in crude chicken bone were selected out manually, and their weight was measured and recorded. The separation rate of chicken meat and bone is shown in Table 5 .

\section{Discussion}

\subsection{Cooking Process}

The results of cooking process in the separation are showed in Table 1. The effect of heating approach to the separation shows that outflow of chicken meat of group $\mathrm{C}$ was the highest with a value of $93.01 \pm 0.269$, which was significantly $(\mathrm{P}<0.05)$ higher than sample A $(81.33 \pm 3.48)$ and sample B $(46.33 \pm 3.76)$. Chicken bone and meat could not be completely separated at $100^{\circ} \mathrm{C}$ for $45 \mathrm{~min}$, there were still some chicken meat left on the bone. However, the separation under $114^{\circ} \mathrm{C}$ for $45 \mathrm{~min}$ was satisfied. After the chicken soup was filtered, the remaining chicken bone and meat was separated manually for next use.

\subsection{Liquid Injection Direction}

\subsubsection{Influence of Liquid Injection Direction on the Rate of Outflow of Chicken Meat}

From Figure 3, the rate of outflow of chicken meat under the tangential direction was higher than the radial direction. This is because the chicken meat can rush out of the separating vessel steadily with the slow spinning rise fluid in the tangential direction, while in the radial direction the meat rolling up and down with the turbulence, resulting in low separation efficiency. Therefore, we can draw the conclusion that the separation under the tangential direction is superior to the radial direction with the same situation in other conditions.

\subsubsection{Influence of Liquid Injection Direction on the Rate of Outflow Rate of the Chicken Bone}

The effect of flow direction on the outflow rate of bone is shown in Table 2. The result of the outflow rate of bone shows that sample B was the highest with a value of $5.92 \pm 1.2$, which was significantly $(P<0.05)$ higher than sample $A(0 \pm 0.41)$. The outflow rate of bone under the radial direction was higher than the tangential direction. It was very clear that the bone can be brought out of the separating vessel easily even under lower flow velocity in the radial direction. The fluid in the separating vessel forms a turbulent in the radial direction, and then results in more outflow of chicken bone. While in

Table 5. Effect of ideal separation conditions on on-site application test.

\begin{tabular}{|c|c|c|c|c|c|c|}
\hline Parameters & $\begin{array}{c}\text { Total crude } \\
\text { meat }(\mathrm{g})\end{array}$ & $\begin{array}{l}\text { Total crude } \\
\text { bone }(\mathrm{g})\end{array}$ & $\begin{array}{l}\text { Total net } \\
\text { meat }(\mathrm{g})\end{array}$ & $\begin{array}{l}\text { Total net } \\
\text { bone }(\mathrm{g})\end{array}$ & $\begin{array}{c}\text { Separation rate } \\
\text { of meat (\%) }\end{array}$ & $\begin{array}{c}\text { Separation rate } \\
\text { of bone (\%) }\end{array}$ \\
\hline $\begin{array}{l}\text { Tangential direction Impel } \\
\text { speed: } 200 \mathrm{r} / \mathrm{min} \text { Flow } \\
\text { velocity: } 0.80 \mathrm{~cm} / \mathrm{s}\end{array}$ & 661.43 & 315.74 & 595.25 & 299.12 & 90.35 & 95.76 \\
\hline
\end{tabular}


the tangential direction, the bone is kept down at the bottom of the separating vessel with slow spinning rise fluid. There are a few bones that flow out with the fluid in the practical separation process. It was observed that the outflow of the bones is mainly cartilage. So it can be determined that the tangential flow can effectively prevent the outflow of the bone.

\subsection{Impeller Speed}

\subsubsection{Influence of Impeller Speed on the Rate of Outflow Rate of the Meat}

According to Figure 4, the outflow rate of meat was obviously higher under the impeller speed of $200 \mathrm{r} / \mathrm{min}$ than $0 \mathrm{r} / \mathrm{min}$ in the same amount of time. This indicates that impeller rotational helps the separation work of chicken skeleton.

\subsubsection{Influence of Impeller Speed on the Rate of Outflow Rate of the Bone} The effect of impeller speed on the outflow rate of bone is shown in Table 3. The result of the outflow rate of bone shows that sample A was the highest with a value of $2.77 \pm$ 0.64 , which was significantly $(\mathrm{P}<0.05)$ higher than sample $\mathrm{B}(0.633 \pm 0.38)$.

It can be determined that an effective separating process chicken meat and bone from chicken skeleton was developed by the impeller speed at $200 \mathrm{r} / \mathrm{min}$.

\subsection{Liquid Level Rising Velocity}

\subsubsection{Influence of the Liquid Level Rising Velocity on the Rate of Outflow of Chicken Meat}

From Figure 5, the higher the flow velocity, the higher the rate of chicken meat outflow. The reason causing the above phenomenon is that the meat can be easily carried out to the filter with the increasing flow velocity. However, after more than $0.80 \mathrm{~cm} / \mathrm{s}$, the rate of increase of the liquid level rising velocity had no significant effect on the outflow rate of meat.

\subsubsection{Influence of the Liquid Level Rising Velocity on the Rate of Outflow of Chicken Bone}

The result of effect of liquid level rising velocity on the outflow rate of bone is shown in Table 4. The result of the outflow rate of bone shows that sample $\mathrm{C}$ was the highest with a value of $3.33 \pm 0.33$, which was significantly $(\mathrm{P}<0.05)$ higher than sample A $(0 \pm$ $0.00)$ sample $B(0.633 \pm 0.38)$. From Table 3 the outflow rate of bone increased with the impeller speed and the flow velocity. Only a very small amount of cartilage flowed out, as long as the flow velocity control at $1.0 \mathrm{~cm} / \mathrm{s}$ or below under the impeller speed of 200 $\mathrm{r} / \mathrm{min}$. At $1.0 \mathrm{~cm} / \mathrm{s}$ liquid level rising velocity the suspension rotates too fast, resulting in more chicken bones flow out of the separation barrel with chicken meat. The residual chicken bones in meat have increased. If the liquid level rising velocity at $0.6 \mathrm{~cm} / \mathrm{s}$, the suspension rotate intensity is not enough to separate the bottom meat with the chicken bone, and the residual chicken meat in bone have increased as well.

Therefore, the flow velocity must not too fast or too low, which would depress the separation effect. In conclusion, $0.8 \mathrm{~cm} / \mathrm{s}$ is the optimum liquid level rising velocity. 


\subsection{Practical Application}

From Table 5, under the ideal separating conditions, chicken meat and bone can be separated out from chicken skeleton effectively with net separation efficiency of more than $90 \%$ for chicken meat and $95 \%$ for bone. The chicken bone doped in the outflow meat is negligible, and there are almost no residual meats in the separated bone, all have no effect on the subsequent processing. The actual separation effect is satisfactory with strong feasibility and operability of the program. So the best separation parameters of the separation equipment for tangential direction, impeller speed at $200 \mathrm{r} / \mathrm{min}$, the liquid level rising velocity at $0.80 \mathrm{~cm} / \mathrm{s}$.

\section{Conclusion}

Pressure cooking enhanced the separation process of chicken meat from chicken bone. Tangential flow kept the liquid flow stable and enabled chicken meat flow out of the separation kettle smoothly. Auxiliary mixing was conducive to the separation of chicken bone. The separation rate of meat and bone reached maximum value at the flow velocity of $0.80 \mathrm{~cm} / \mathrm{s}$. Based on the results above, the optimal conditions for the separation of the chicken skeleton were heating the chicken skeleton at $114^{\circ} \mathrm{C}$ for $45 \mathrm{~min}$, pumping the liquid injection in tangential direction, the impeller speed at $200 \mathrm{r} / \mathrm{min}$ and the liquid level rise rate at $0.8 \mathrm{~cm} / \mathrm{s}$. To sum up, through the optimization of the separation parameters and the methods, the equipment we designed can maximize its advantages, which is worthy for further research and application.

\section{Acknowledgements}

Gratitude is expressed to Administration of Ocean and Fisheries of Guangdong Province (A201600C05) and China Ministry of Agriculture (2014GB2E00037) for funding this research program. Appreciate is expressed to Shanwei Liqun Agriculture Development Co., Ltd for their technical assistance and support.

\section{References}

[1] National Bureau of Statistics of China (2014) China Statistical Yearbook. China Statistics Press, Beijing. (In Chinese)

[2] Olmedilla-Alonso, B., Jiménez-Colmenero, F. and Sánchez-Muniz, F.J. (2013) Development and Assessment of Healthy Properties of Meat and Meat Products Designed as Functional Foods. Meat Science, 95, 919-930. https://doi.org/10.1016/j.meatsci.2013.03.030

[3] Barbut, S. (2016) Poultry Products Processing: An Industry Guide. CRC Press, Boca Raton.

[4] Jayathilakan, K., Sultana, K., Radhakrishna, K. and Bawa, A.S. (2012) Utilization of Byproducts and Waste Materials from Meat, Poultry and Fish Processing Industries: A Review. Journal of Food Science and Technology, 49, 278-293. https://doi.org/10.1007/s13197-011-0290-7

[5] Zhao, D., Chen, X., Bai, Y. and Zhang, X. (2010) Development and Utilization of Bones from By-Products of Slaughtered Animals. Meat Research, 1, 015.

[6] Zhang, W., Xiao, S., Samaraweera, H., Lee, E.J. and Ahn, D.U. (2010) Improving Functional Value of Meat Products. Meat Science, 86, 15-31. 
https://doi.org/10.1016/j.meatsci.2010.04.018

[7] Lasekan, A., Bakar, F.A. and Hashim, D. (2013) Potential of Chicken By-Products as Sources of Useful Biological Resources. Waste Management, 33, 552-565.

https://doi.org/10.1016/j.wasman.2012.08.001

[8] Toldrá, F., Aristoy, M.C., Mora, L. and Reig, M. (2012) Innovations in Value-Addition of Edible Meat By-Products. Meat Science, 92, 290-296.

https://doi.org/10.1016/j.meatsci.2012.04.004

[9] Brandelli, A., Sala, L. and Kalil, S.J. (2015) Microbial Enzymes for Bioconversion of Poultry Waste into Added-Value Products. Food Research International, 73, 3-12. https://doi.org/10.1016/j.foodres.2015.01.015

[10] Froning, G.W. and McKee, S.R. (2010) Mechanical Separation of Poultry Meat and Its Use in Products. Poultry Meat Processing. CRC Press, Boca Raton, 295-309.

https://doi.org/10.1201/b15805-15

[11] Simonin, H., Duranton, F. and De Lamballerie, M. (2012) New Insights into the HighPressure Processing of Meat and Meat Products. Comprehensive Reviews in Food Science and Food Safety, 11, 285-306. https://doi.org/10.1111/j.1541-4337.2012.00184.x

[12] Lafarga, T. and Hayes, M. (2014) Bioactive Peptides from Meat Muscle and By-Products: Generation, Functionality and Application as Functional Ingredients. Meat Science, 98, 227-239. https://doi.org/10.1016/j.meatsci.2014.05.036

[13] Kettawan, A., Sungpuag, P., Sirichakwal, P. and Chavasit, V. (2002) Chicken Bone Calcium Extraction and Its Application as a Food Fortificant. Journal of the National Research Council of Thailand (Thailand).

[14] Sun, H.M., Wang, J.Z., Zhang, C.H., Li, X., Xu, X., Dong, X.B. and Li, C.H. (2014) Changes of Flavor Compounds of Hydrolyzed Chicken Bone Extracts during Maillard Reaction. Journal of Food Science, 79, C2415-C2426. https://doi.org/10.1111/1750-3841.12689

[15] Bibwe, B.R., Hiregoudar, S., Nidoni, U.R., Anantachar, M. and Shrestha, B. (2013) Development of Meat-Bone Separator for Small Scale Fish Processing. Journal of Food Science and Technology, 50, 763-769. https://doi.org/10.1007/s13197-011-0381-5

[16] Tien, C.M.T., Thai-Quang, N., Mai-Duy, N., Tran, C.D. and Tran-Cong, T. (2014) A Fully Coupled Scheme for Viscous Flows in Regular and Irregular Domains Using Compact Integrated RBF Approximation. Applied Mechanics and Materials, 553, 138-143. https://doi.org/10.4028/www.scientific.net/AMM.553.138 
Submit or recommend next manuscript to SCIRP and we will provide best service for you:

Accepting pre-submission inquiries through Email, Facebook, LinkedIn, Twitter, etc. A wide selection of journals (inclusive of 9 subjects, more than 200 journals)

Providing 24-hour high-quality service

User-friendly online submission system

Fair and swift peer-review system

Efficient typesetting and proofreading procedure

Display of the result of downloads and visits, as well as the number of cited articles

Maximum dissemination of your research work

Submit your manuscript at: http://papersubmission.scirp.org/

Or contact fns@scirp.org 